\title{
Design of the Evaluation Index System of the Intelligence Level of the Smart Metering Supply Chain
}

\author{
Yanan Liu ${ }^{a}$, Jingzhi Ding ${ }^{b}$ \\ School of Beijing Jiaotong University, Beijing 100089, China \\ a16120580@bjtu.edu.cn, bjzding@bjtu.edu.cn
}

Keywords: Measurement supply chain, Intelligence, Evaluation index system, Analytic hierarchy process.

\begin{abstract}
This article discusses the transition requirements and development direction of each subsidiary from the "great marketing" system of the State Grid. Based on the analysis of various factors affecting the measurement supply chain, it constructs an evaluation index system for the intelligence level of the measurement intelligence supply chain. The use of the analytic hierarchy process to rank the impact factors provides a basis for business decisions.
\end{abstract}

\section{Introduction}

In order to implement the requirements of "group operation, intensive development, lean management, and standardization construction" of the State Grid Corporation of China, it supports the smooth operation of the "big marketing" system, accelerates the pace of market-oriented transformation with the customer as the core, and the national power grid stands on the supply of wisdom. From the perspective of the chain, higher requirements are placed on the supply chain of the electric energy metering devices of the subsidiaries. At present, the State Grid has established a complete set of asset life-cycle management assessment index systems covering all measurement business segments with clear levels, but the overall system focuses on the performance assessment of one business link, and does not highlight the degree of intelligence. ,, Only used as a performance appraisal for provincial branches, and it is of little significance to measure the future development direction of smart supply chain. In addition, due to the differences in the capabilities, technical levels, and management methods of energy supply metering equipment supply chain business in each province, the universal evaluation index system established at the State Grid level is not targeted and cannot fully reflect the provincial characteristics. We need to establish a feasible and scientific evaluation index system to measure the intelligence level of production supply chain, and help them to more intuitively see the degree of development and direction of development of the measurement production supply chain. Therefore, how to accurately grasp the development status of measurement and construct a set of evaluation index system that comprehensively evaluates the intelligence level of the production supply chain, and provide basis for the grid company to review, evaluate, manage, and guide the level of self-development, and the auxiliary measurement center is more intuitive. See the intelligent development level and development direction of the measurement production supply chain, so as to realize the strategic goal of "service quality". Therefore, we do further research on the evaluation system of the wisdom of the measurement production supply chain.

By referring to relevant national policy standards and reading related documents, this article has learned that domestic and foreign scholars have conducted a lot of research on the performance assessment of production-wide supply chain. Hour Xing he et al. (2003)[1] pointed out the main connotations of the supply chain of electric energy metering devices and proposed that the construction of a set of evaluation systems that conform to the supply chain of electric energy metering devices can guide the management of the electric energy metering device supply chain. Ma Shihua et al. (2000) [2] proposed evaluation indicators that can reflect the performance of the entire supply chain business process, including: supply chain overall operating cost indicators, supply chain product quality indicators, and production-demand rate indicators. Zhou Ye et al. (2007)[3] proposed 
a set of supply chain performance evaluation index system based on the life cycle, starting from the characteristics of the formation period, development period, and maturity of the supply chain, and analyzing the evaluation focus of each period. Li Yuen et al. (2017)[4] built a smart supply chain performance evaluation model through indicators such as supply chain management awareness, planning, procurement, production, flexibility, and intelligence. However, the above research is limited to the production of full supply chain performance evaluation research, there is no intelligent evaluation model. On the basis of the above-mentioned supply chain performance evaluation system, this paper expands the evaluation of production supply chain to cover the entire life cycle of procurement, arrival, acceptance, verification, storage, and distribution of electric energy metering devices, and proposes an intelligent level of production supply chain for metering devices. The evaluation index system assists the enterprise to more intuitively see the development level and development direction, in order to provide reference and reference for advancing the intelligent level management of the intelligent supply chain of electric energy measurement devices.

\section{Overview of the Smart Supply Chain for Electric Energy Metering Devices}

\subsection{Energy Metering Device Supply Chain.}

The nodes involved in the supply chain of electric energy metering devices mainly include electric energy metering device suppliers, electric energy metering centers, power supply bureaus, and power supply companies. Electric Energy Metering Center is an electric energy metering and testing agency for the electric power industry. It is responsible for the management of the entire life cycle of the assets of electric energy metering devices in the area, and is responsible for the whole life cycle management of electric energy metering devices, including procurement, warehousing, verification, distribution, recycling, quality inspection, etc. Link. In the entire chain, the power supply bureau and the power supply company summarize the user demand and submit a demand plan to the measurement center. After the measurement center receives the reported demand, it arranges the procurement task and submits the purchase order to the supplier. The supplier supplies the measurement center with the order according to the order. . After the arrival of the electric energy metering device, it passes the sample comparison, full performance test, sampling inspection, etc., and then the production department arranges the production according to the determined production plan and delivery date. According to the model of the electric meter, the resources are distributed to the corresponding inspection machines and passed. Determine the production time and orderly arrangement of production equipment after the production work is completed, the metering device is put into storage. After that, it enters the distribution stage. The metering center collects various types of product orders, selects the most suitable delivery vehicle, the optimal distribution route, and the most appropriate delivery time for distribution, while processing the old device for recycling.

\subsection{Smart Supply Chain.}

Today's society is moving from the era of information (IT) to the era of data processing (DT). New technologies such as big data and cloud computing are booming, and measurement production is bound to enter a new stage, the phase of smart supply chain. Lou Gang first proposed the concept of smart supply chain at the Shanghai Informatization and Industrialization Convergence Conference (2009). Smart supply chain refers to the theories, methods, and technologies that combine Iota technology and modern supply chain management. It is built between companies and enterprises. , to achieve the supply chain of intelligent, networked and automated technology and management integrated system. In 2015, the State "Electricity Change No. 9 Document" was promulgated, and the market for sale of electricity was released. The grid company has deepened its large-scale marketing system and achieved more intensive and flat management of metering business. It has begun the transition to a smart supply chain for electric energy metering devices. Past procurement plans have been transformed from "passive acceptance" to "active acquisition" through digitalization. In the past, production plans based on human experience were basically transformed from production to storage through "data-driven" production. Warehousing and distribution links have gradually changed from "experienced" to "scientific". 


\subsection{Intelligent.}

The level of intelligence in a company's supply chain embodies the wisdom of a smart supply chain. For example, in the production phase, the measurement center intelligently tracks and monitors the production process through three-dimensional configuration, video monitoring, and production of real-time data, and delays and plans for verification of production plans due to arrival, equipment failures, and system upgrades. Adjustments, etc., timely implementation progress and deviations, and rolling amendments, reductions in management level, making the entire production process more orderly, improving the automation, intelligence, and refined management of production management, effectively improving inventory turnover and reducing Safe inventory, reduced costs.

\section{Construction of an Intelligent Evaluation Index System for Smart Supply Chain Intelligence of Energy Metering Devices}

\subsection{Design Ideas of Indicator System.}

In order to measure the current development of the measurement of smart production, according to the principle of data availability and renewable, we focus on the key aspects of the measurement supply chain from the level of intelligence and use the degree of intelligence as the evaluation criteria, focusing on time, cost, quality, and risk. The core elements, such as strategic, operational, and basic levels, have established an evaluation index system for the production of intelligent electric energy metering devices, and evaluated and closed-loop management of metered smart production.

According to the current national regulations and the corresponding indicators of industry regulations, an analytic hierarchy process and an SCOR model are used to build an intelligent evaluation index system for the supply chain intelligence of electric energy metering devices to truly reflect the intelligence level of the supply chain of electric energy metering devices. Improvements and improvements.

\subsection{Design Evaluation Index System Model.}

Analytic hierarchy process is an extremely effective method to convert semi-qualitative and semi-quantitative problems into quantitative calculations. [5] The so-called hierarchy is based on the nature of the problem under study and the objectives to be achieved. The problem is decomposed into different components, and all factors are aggregated according to the mutual influence and affiliation of each factor, forming a Multi-level analysis of structural models. Based on the current national regulations and relevant indicators of industry regulations, we base on the basic principles of SCOR, and based on the influencing factors of total quality management of people, machines, materials, methods, rings, and surveys. They are classified and stratified to form a hierarchical structure as shown in Table 1. It is mainly divided into four layers. The first layer is the target level, that is, the intelligence level of the appraisal and measurement supply chain; the second layer considers the main influencing factors to the total target through the three levels of enterprise strategy, operation, and basic level: the level of intelligent operation management, The level of decision support intelligence and the level of production process automation; the third level is the specific decomposition of the second level of indicators, through the use of the basic principles of SCOR, from the plan (P), procurement $(\mathrm{S})$, production $(\mathrm{M})$, distribution $(\mathrm{D})$ and return $(\mathrm{R})$ to start with the five basic processes, consider the impact of factors around the level of intelligence. The fourth-level indicator is the subdivision of specific quantitative assessment indicators for the third-tier indicators. 
Table 1. Evaluating Indicator System of Smart Supply Chain Intelligence Level

\begin{tabular}{|c|c|c|c|c|c|c|}
\hline $\begin{array}{c}\text { First-level } \\
\text { indicators A }\end{array}$ & No. & $\begin{array}{c}\text { Secondary } \\
\text { indicators B }\end{array}$ & No. & $\begin{array}{l}\text { Third-level } \\
\text { indicators C }\end{array}$ & No. & Four indicators D \\
\hline \multirow{34}{*}{$\begin{array}{c}\text { Measure } \\
\text { supply chain } \\
\text { intelligence } \\
\text { level }\end{array}$} & \multirow{13}{*}{1} & \multirow{13}{*}{$\begin{array}{c}\text { Operational } \\
\text { management } \\
\text { intelligence } \\
\text { level }\end{array}$} & \multirow{4}{*}{1} & \multirow{4}{*}{$\begin{array}{c}\text { Production } \\
\text { Management } \\
\text { Collaboration Level }\end{array}$} & 1 & Demand satisfaction rate \\
\hline & & & & & 2 & Verification efficiency \\
\hline & & & & & 3 & Old table sorting ability \\
\hline & & & & & 4 & Storage utilization level \\
\hline & & & \multirow{4}{*}{2} & \multirow{4}{*}{$\begin{array}{l}\text { Operational } \\
\text { excellence }\end{array}$} & 5 & Plan execution accuracy \\
\hline & & & & & 6 & Plan execution flexibility \\
\hline & & & & & 7 & Plan to track monitoring capabilities \\
\hline & & & & & 8 & Automatic operation and maintenance capabilities \\
\hline & & & \multirow{3}{*}{3} & \multirow{3}{*}{$\begin{array}{l}\text { Data resource } \\
\text { utilization }\end{array}$} & 9 & Information System Utilization \\
\hline & & & & & 10 & System dependencies \\
\hline & & & & & 11 & Data Mining Level \\
\hline & & & \multirow{2}{*}{4} & \multirow{2}{*}{$\begin{array}{c}\text { Customer service } \\
\text { level }\end{array}$} & 12 & Customer share \\
\hline & & & & & 13 & Service satisfaction \\
\hline & \multirow{8}{*}{2} & \multirow{8}{*}{$\begin{array}{c}\text { Decision } \\
\text { support } \\
\text { intelligence } \\
\text { level }\end{array}$} & \multirow{3}{*}{5} & \multirow{3}{*}{$\begin{array}{l}\text { Procurement } \\
\text { accuracy }\end{array}$} & 14 & Demand acquisition timeliness \\
\hline & & & & & 15 & Matching degree of demand \\
\hline & & & & & 16 & purchase cost \\
\hline & & & \multirow{3}{*}{6} & \multirow{3}{*}{$\begin{array}{l}\text { Flexible test } \\
\text { capabilities }\end{array}$} & 17 & Emergency plug-in response rate \\
\hline & & & & & 18 & Emergency plug-in average response time \\
\hline & & & & & 19 & Task scheduling flexibility \\
\hline & & & \multirow{2}{*}{7} & \multirow{2}{*}{ Smart logistics } & 20 & Reasonable storage layout \\
\hline & & & & & 21 & Flexible distribution capabilities \\
\hline & \multirow{13}{*}{3} & \multirow{13}{*}{$\begin{array}{l}\text { Production } \\
\text { process } \\
\text { automation } \\
\text { level }\end{array}$} & \multirow{3}{*}{8} & \multirow{3}{*}{$\begin{array}{c}\text { Demand forecast } \\
\text { level }\end{array}$} & 22 & Time Series Forecast Accuracy \\
\hline & & & & & 23 & Customer Series Forecast Accuracy \\
\hline & & & & & 24 & Equipment Series Forecast Accuracy \\
\hline & & & \multirow{5}{*}{9} & \multirow{5}{*}{$\begin{array}{c}\text { Automatic } \\
\text { verification rate }\end{array}$} & 25 & Single-phase meter automatic verification rate \\
\hline & & & & & 26 & Three-phase table automatic verification rate \\
\hline & & & & & 27 & Acquisition terminal automatic verification rate \\
\hline & & & & & 28 & Current transformer automatic verification rate \\
\hline & & & & & 29 & Old table sorting automatic verification rate \\
\hline & & & \multirow{2}{*}{10} & \multirow{2}{*}{$\begin{array}{l}\text { Production process } \\
\text { capability }\end{array}$} & 30 & Production quality level \\
\hline & & & & & 31 & Production management capabilities \\
\hline & & & \multirow{3}{*}{11} & & 32 & Central Library Operation Automation Rate \\
\hline & & & & Storage automation & 33 & Level 2 library operation automation rate \\
\hline & & & & & 34 & Station turnover container allocation rate \\
\hline
\end{tabular}

\subsection{Constructing a Comparison Matrix and Performing a Consistency Test.}

Based on the factors affecting the intelligence level of the measurement supply chain, a comparison matrix is established, that is, the importance value of each layer element to the upper layer element. Assuming that the elements of the A layer are related to the underlying elements, a comparison matrix is created with the following form:

$$
\left[\begin{array}{rrrrr}
A_{K} & B_{1} & B_{2} & \ldots & B_{n} \\
B_{1} & B_{11} & B_{21} & \ldots & B_{n 1} \\
B_{2} & B_{12} & B_{22} & \ldots & B_{n 2} \\
\vdots & \vdots & \vdots & & \vdots \\
B_{m} & B_{1 m} & B_{2 m} & \ldots & B_{n m}
\end{array}\right]
$$

After comprehensively understanding and measuring the various indicators of the measurement system of the supply chain intelligence level, determine the judgment matrix of each factor as shown in Table 2 - Table 5.

Table 2. Judgment Matrix for Comprehensive Evaluation of the Level of Intelligence

\begin{tabular}{|c|c|c|c|}
\hline A & B1 & B2 & B3 \\
\hline B2 & 1 & $1 / 3$ & 3 \\
\hline B2 & 3 & 1 & 5 \\
\hline B3 & $1 / 3$ & $1 / 5$ & 1 \\
\hline
\end{tabular}


Table 3. Evaluation of Operational Management Intelligence Level

\begin{tabular}{|c|c|c|c|c|}
\hline B1 & C1 & C2 & C3 & C4 \\
\hline C1 & 1 & $1 / 5$ & $1 / 3$ & $1 / 3$ \\
\hline C2 & 5 & 1 & 2 & 2 \\
\hline C3 & 3 & $1 / 2$ & 1 & 1 \\
\hline C4 & 3 & $1 / 2$ & 1 & 1 \\
\hline
\end{tabular}

Table 4. Evaluation level of decision support intelligence

\begin{tabular}{|c|c|c|c|}
\hline B2 & C5 & C6 & C7 \\
\hline C5 & 1 & 3 & 5 \\
\hline C6 & $1 / 3$ & 1 & 2 \\
\hline C7 & $1 / 5$ & $1 / 2$ & 1 \\
\hline
\end{tabular}

Table 5. Evaluation of the level of automation in the production process

\begin{tabular}{|c|c|c|c|c|}
\hline B3 & C8 & C9 & C10 & C11 \\
\hline C8 & 1 & 5 & $1 / 2$ & $1 / 3$ \\
\hline C9 & $1 / 5$ & 1 & 2 & 2 \\
\hline C10 & 2 & $1 / 2$ & 1 & 1 \\
\hline C11 & 3 & $1 / 2$ & 1 & 1 \\
\hline
\end{tabular}

\subsection{Consistency Check.}

If the judgment matrix given by the decision-maker is the same, it means that the decision-maker's pairwise comparison of various factors can be passed, that is, the decision-maker makes a comparison to judge that the thinking is consistent. If there is no consistency, then the judgment matrix can't really reflect the proportion of each element. Methods as below:

First calculate the hierarchical single-order consistency index:

$$
\mathrm{CI}=\frac{\lambda_{\max }-\mathrm{n}}{\mathrm{n}-1}
$$

In the formula, CI can be regarded as the degree of deviation of the judgment matrix from the consistency. But in the end, we need to judge whether the matrix has satisfactory consistency through the consistency ratio $\mathrm{CR}$ of the matrix. When $\mathrm{CR}<0.1$, we can think that the judgment matrix has satisfactory consistency.

$$
\mathrm{CR}=\frac{\mathrm{CI}}{\mathrm{RI}}
$$

Among them, RI is the average random consistency index. For a particular $\mathrm{n}$, a positive reciprocal matrix is randomly constructed, and the matrix elements are randomly selected from $1,2, \ldots, 9,1 / 2$, $1 / 3, \ldots, 1 / 9$. Take a sufficiently large subsample (eg, 500 samples) to find the average of the largest eigenvalues of the matrix.

$$
\mathrm{RI}=\frac{\lambda-\mathrm{n}}{\mathrm{n}-1}
$$

Table 6. For the 1-9th order judgment matrix, Satty gives the value of RI

\begin{tabular}{|c|c|c|c|c|c|c|c|c|c|}
\hline $\mathrm{N}$ & 1 & 2 & 3 & 4 & 5 & 6 & 7 & 8 & 9 \\
\hline $\mathrm{RI}$ & 0 & 0 & 0.58 & 0.90 & 1.12 & 1.24 & 1.32 & 1.41 & 1.45 \\
\hline
\end{tabular}

Table 7. From this we can calculate the consistency ratio of the judgment matrix

\begin{tabular}{|c|c|c|c|c|}
\hline & $\mathrm{A}$ & $\mathrm{B}_{1}$ & $\mathrm{~B}_{2}$ & $\mathrm{~B}_{3}$ \\
\hline $\mathrm{CR}$ & 0.40 & 0.001 & 0.03 & 0 \\
\hline
\end{tabular}

The hierarchical total order consistency test results are:

$$
\mathrm{CR}=\frac{C I}{R I}=0.026<0.1
$$

The results show that the matrix is acceptable.

\subsection{Calculating Combination Weight Vectors.}

The total ranking of each influencing factor relative to the total goal is shown in Table 8 . 
Table 8 Combination weight vector and sorting

\begin{tabular}{|c|c|cc|}
\hline Criteria layer & Indicator layer & Weights & order \\
\hline B1 & C1 & 0.023 & 11 \\
& C2 & 0.054 & 8 \\
& C3 & 0.231 & 1 \\
B2 & C4 & 0.138 & 3 \\
& C5 & 0.085 & 4 \\
B3 & C6 & 0.198 & 2 \\
& C7 & 0.068 & 7 \\
& C8 & 0.075 & 6 \\
& C9 & 0.078 & 5 \\
& C10 & 0.028 & 10 \\
& C11 & 0.032 & 9 \\
\hline
\end{tabular}

\section{Conclusion}

(1) From the perspective of overall ranking, the utilization of data resources is a prerequisite for reflecting the intelligence of the supply chain. In the entire chain, the accuracy of demand forecasting affects the subsequent series of links, and the accuracy of demand forecasting mainly depends on data capture. Take the accuracy. In addition, there are a large number of data interactions in the procurement, production, distribution, recycling, etc. Therefore, the utilization of data resources affects the accuracy of the work and is a prerequisite for intelligence.

(2) Flexible verification capability is at the core of the entire chain operation. Production capacity not only limits the demand level, but also affects the subsequent delivery service level.

(3) Customer service level affects customer satisfaction and is one of the important means to help companies find problems and improve services.

\section{References}

[1]. Hour Xing he, Ma Hong in, Yang Chun, Ding Song. Research on Supply Chain Management Strategy of Electric Energy Measuring Instruments [J]. China Logistics \& Purchasing, 2012(08):66-67.

[2]. Ma Shisha, Chen Taxi. Research on the Component Factors and Evaluation Methods of Logistics Service Capability Based on Supply Chain [J]. Computer Integrated Manufacturing Systems, 2007(04):744-750.

[3]. Lou Ming, Ma Wei, Zhou Ye. Performance Evaluation Index System in the Life Cycle of Supply Chain [J]. Logistics Technology, 2007 (10)

[4]. Li Yuen, Xing Lanolin. Construction of Performance Evaluation Index System for Smart Supply Chain [J]. Statistics and Decision, 2017(03):183-185.

[5]. Lin Wining. Decision Analysis [M]. Beijing: Beijing University of Posts and Telecommunications Press, 2003. 